\title{
Treatment outcome and toxicity of intensity-modulated (chemo) radiotherapy in stage III non-small cell lung cancer patients
}

\author{
Stephanie LA Govaert ${ }^{1}$, Esther GC Troost ${ }^{1}$, Olga CJ Schuurbiers ${ }^{2}$, Lioe-Fee de Geus-Oei ${ }^{3}$, Ariën Termeer ${ }^{4}$,
} Paul N Span ${ }^{1}$ and Johan Bussink ${ }^{1^{*}}$

\begin{abstract}
Purpose: The aim of this retrospective cohort study was to assess treatment outcome, and acute pulmonary and esophageal toxicity using intensity modulated (sequential/concurrent chemo)radiotherapy (IMRT) in locally advanced stage III non-small cell lung cancer (NSCLC).

Methods and materials: Eighty-six patients with advanced stage NSCLC, treated with either IMRT only (66 Gy) or combined with (sequential or concurrent) chemotherapy were retrospectively included in this study. Overall survival and metastasis-free survival were assessed as well as acute pulmonary and esophageal toxicity using the RTOG Acute Radiation Morbidity Scoring Criteria.

Results: Irrespective of the treatment modality, the overall survival rate for patients receiving 66 Gy was $71 \%$ $( \pm 11 \% ; 95 \% \mathrm{Cl})$ after one year and $56 \%( \pm 14 \%)$ after two years resulting in a median overall survival of 29.7 months. Metastasis-free survival was $73 \%( \pm 11 \%)$ after both one and two years. There were no statistically significant differences between the treatment groups. Treatment related esophageal toxicity was significantly more pronounced in the concurrent chemoradiotherapy group $(p=0.013)$ with no differences in pulmonary toxicity.

Conclusions: This retrospective cohort study in advanced non-small cell lung cancer patients shows that IMRT is an effective technique with acceptable acute toxicity, also when (sequentially or concomitantly) combined with chemotherapy.
\end{abstract}

Keywords: Intensity-modulated (chemo)radiotherapy, Stage III non-small cell lung cancer

\section{Introduction}

Lung cancer is an increasing cause of death in developing and developed countries, accounting for 1.39 million deaths worldwide in 2008. Non-small cell lung cancer (NSCLC) accounts for approximately $85 \%$ of all lung cancer cases [1]. The treatment of choice for individuals with local NSCLC, stage I, II and IIIA (T3N1), is surgical resection. Based on large series of resected stage I and II NSCLC, five-year survival rates are commonly reported to be 60 to $80 \%$ and 40 to $50 \%$, respectively [2]. In patients with locally advanced NSCLC, stage IIIA (N2) and IIIB,

\footnotetext{
* Correspondence: j.bussink@rther.umcn.nl

'Department of Radiation Oncology, Radboud University Nijmegen Medical Centre, PO Box 9101, Nijmegen 6500 HB, The Netherlands

Full list of author information is available at the end of the article
}

concurrent radiochemotherapy is recommended [3,4]. However, survival rates with these approaches are only in the order of $15 \%$, and a lot of patients are not eligible to undergo this intensified regimen $[5,6]$. Considering the fact that treatment failure most often occurs at the primary tumor site, improvement in overall survival of locally advanced stage III NSCLC can be achieved through better local control. A meta-analysis by Aupérin et al. proved concurrent regimens to be superior to sequential ones in terms of locoregional control and overall survival [5]. In concurrent schedules, the chemotherapeutic agents enhance the tumor's radiosensitivity and thus the local treatment efficacy, but this comes at the cost of increased toxicity.

\section{Biomed Central}

(c) 2012 Govaert et al.; licensee BioMed Central Ltd. This is an Open Access article distributed under the terms of the Creative Commons Attribution License (http://creativecommons.org/licenses/by/2.0), which permits unrestricted use, distribution, and reproduction in any medium, provided the original work is properly cited. 
Apart from the concurrent administration of chemotherapy, another approach to accomplish better locoregional control is dose escalation. Several studies have shown that this strategy improves local control and consequently overall survival of locally advanced stage III NSCLC [7-11]. Using three-dimensional conformal radiation therapy (3D-CRT) allows dose escalation without excessive toxicity, while improving overall survival rates [12,13]. Compared with 3D-CRT, intensitymodulated radiation therapy (IMRT) enables even tighter sculpting of high-dose regions around the tumor volume, creates steep dose gradients and thus reduces radiation dose to surrounding normal tissues, ultimately facilitating dose-escalation [14]. Therefore, the University of Texas M.D. Anderson Cancer Center investigated the rate of high-grade treatment-related pneumonitis in patients with advanced NSCLC treated with concurrent chemotherapy and IMRT. Toxicity rates were compared with a similar cohort of patients treated with 3D-CRT (median radiation dose 63 Gy for both treatment modalities). The levels of Grade $\geq 3$ radiation pneumonitis at 12 months according to RTOG toxicity scoring [15] were significantly $(p=0.002)$ lower for IMRT than for 3D-CRT, being $8 \%$ (95\% CI 4\%-19\%) and $32 \%$ (95\% CI 26\%-40\%), respectively [16]. This initial evaluation is consistent with the conclusion of a subsequent study of the institution in larger patient groups and with longer follow-up times [17]. Of the 496 NSCLC patients, 318 were treated with CT/3DCRT and 91 with 4DCT/IMRT. The hazard ratio for 4DCT/IMRT was 0.33 (95\% CI 0.13-0.82; $p=0.017$ ) for Grade $\geq 3$ radiation pneumonitis, indicating lower toxicity rates were associated with 4DCT/IMRT. These findings were confirmed by other studies $[14,18]$. Furthermore, IMRT reduces radiation doses to the esophagus, heart and spinal cord $[18,19]$.

Published clinical data on outcome and toxicity using IMRT in stage III NSCLC are scarce. Therefore, the aim of the present retrospective cohort study was to evaluate outcome, and acute pulmonary and esophageal toxicity using intensity modulated (sequential/concurrent chemo)radiotherapy in locally advanced stage III NSCLC.

\section{Methods and materials}

\section{Patient characteristics}

All patients with advanced-stage irresectable NSCLC treated with curative intent at our institution between March 2008 and February 2011, eighty-six in total, were retrospectively included in this study. All research was carried out in compliance with the Helsinki Declaration and in accordance with Dutch law. The Institutional Review Board waved review due to the retrospective nature of this study. All primary tumors and the mediastinal N2 disease were cytologically or histologically proven. Prior to treatment initiation, patients underwent total body ${ }^{18} \mathrm{~F}$-fluorodeoxyglucose positron emission tomography combined with low dose computed tomography (FDG PET-CT) and MRI scan of the brain for tumor staging purposes. Patients in good general condition were treated with concurrent chemoradiotherapy, those with a contraindication for chemotherapy were treated by radiation alone, and all remaining patients were treated with a sequential chemotherapy and radiotherapy. The planned radiation dose to the primary tumor and metastatic mediastinal lymph nodes using IMRT was 66 Gy in 33 fractions delivered five times per week. Chemotherapeutic agents in the sequential regimen typically consisted of three courses of gemcitabine $\left(1250 \mathrm{mg} / \mathrm{m}^{2}\right.$; on day 1 and 8$)$ and cisplatinum $\left(80 \mathrm{mg} / \mathrm{m}^{2}\right.$; on day 1$)$. The concurrent schedules varied between referring hospitals; in Radboud University Nijmegen Medical Centre it consisted of two courses of etoposide $\left(100 \mathrm{mg} / \mathrm{m}^{2}\right.$; on day $\left.1-3\right)$ and cisplatinum $\left(50 \mathrm{mg} / \mathrm{m}^{2}\right.$; on day 1 and 8), in Canisius-Wilhelmina Hospital one course of gemcitabine/cisplatinum was administered prior to irradiation and two courses of etoposide/cisplatinum concurrently with radiation therapy.

\section{Organ segmentation and treatment planning technique}

The gross tumor volume (GTV) encompassed the primary tumor volume defined on a contrast-enhanced slow-CT scan and the positive mediastinal lymph nodes as defined on CT imaging (short axis $>1 \mathrm{~cm}$ or necrosis). Besides, it included cytologically or histopathologically confirmed pathological FDG-avid lesions. Subsequently, the planning target volume (PTV) was created following the institute's guidelines. Automatic contouring of the lungs and heart was performed using the Pinnacle ${ }^{3}$ treatment planning system (version 8.0 h; Philips Radiation Oncology Systems, Fitchburg, USA). Manual correction was performed if necessary. The esophagus was delineated from the lower border of the cricoid cartilage to the gastro-esophageal junction. The spinal cord was considered to be at the inner margin of the entire bony thoracic spinal canal.

An IMRT treatment plan was generated using a 3D convolution/superposition method for dose calculation, and a standard radiation beam geometry not encompassing the healthy contralateral lung. Multisegment fields were generated for IMRT delivery on a step-and-shoot linear accelerator (Elekta SLi; Elekta $\mathrm{AB}$, Stockholm, Sweden) using six co-planar $10 \mathrm{MV}$ photon beams. Plans had been limited to 60 segments with a minimum segment area of $6 \mathrm{~cm}^{2}$ and at least 10 monitor units. Treatment plans had been optimized using an in-house developed class solution for inverse treatment planning with the direct machine parameter 
optimization algorithm producing deliverable beam segments. All plans had been normalized to a mean dose of 66 Gy in 33 fractions and satisfied the $-5 \%$ and $+7 \%$ dose heterogeneity criteria for the PTV according to ICRU 50/62 guidelines [20,21]. Routinely, position verification was performed using EPID or, from 2009 onwards, MV conebeam-CT imaging with an offline (NAL; no action level [22]) protocol (fraction 1, 2, 3 and weekly thereafter).

\section{Assessment of pulmonary and esophageal toxicity}

During the course of radiation delivery, patient toxicity was weekly assessed by the treating physician according to the RTOG acute toxicity scoring criteria [15]. Pulmonary and esophageal toxicities were scored on a 6 -point scale. For pulmonary toxicity grade 0 was defined as absence of symptoms, grade 1 as mild dry cough or dyspnea on exertion, grade 2 as persistent cough requiring narcotic antitussive agents, grade 3 as severe cough unresponsive to narcotic antitussive agent requiring steroids and intermittent oxygen, and grade 4 as severe respiratory insufficiency requiring continuous oxygen or assisted ventilation. For esophageal toxicity, grade 0 was defined as absence of symptoms, grade 1 as slight symptoms requiring no or nonnarcotic analgesics, grade 2 as symptoms requiring narcotic analgesics and adapted diet, grade 3 as severe dysphagia with dehydration or weight loss requiring nasogastric tube feeding of intravenous fluids, and grade 4 complete obstruction, ulceration, perforation or fistula. For both toxicities grade 5 was considered toxicity related death.

\section{Statistical analysis}

We retrospectively reviewed the records of the patients in the cohort until March 31, 2011. Clinical end points were overall survival and metastasis-free survival. Metastasis-free survival was based on clinical basis and, if metastases were suspected, adequate imaging was performed, e.g., liver ultrasound, CT of thorax/abdomen, FDG-PET or bone-scan. These clinical end points with respect to the different treatment groups were calculated using the Kaplan-Meier method (GraphPad Prism, version 4.0, GraphPad Software, La Jolla, USA). Due to the retrospective nature of this study including patients from several referring hospitals, no reliable data on local and regional control were available and thus not analyzed. For comparison of pulmonary and esophageal toxicity between the different treatment schedules, the chi-square test was used. A $p$-value below 0.05 indicated statistical significance and was assessed using Log Rank test.
Table 1 Patient characteristics $(n=86)$; TNM classification according to $7^{\text {th }}$ edition of International Association for the Study of Lung Cancer

\begin{tabular}{|c|c|}
\hline $\begin{array}{l}\text { Age (y) } \\
\text { median [range] }\end{array}$ & $67.2[44.6 ; 82.7]$ \\
\hline \multicolumn{2}{|l|}{ Morphology (n) } \\
\hline squamous cell carcinoma & 33 \\
\hline adenocarcinoma & 34 \\
\hline neuroendocrine carcinoma & 1 \\
\hline non-small cell carcinoma & 3 \\
\hline \multicolumn{2}{|l|}{ Stage $(n)$} \\
\hline$\| \mathrm{B}$ & 3 \\
\hline$\| I I A$ & 53 \\
\hline$\| I \mathrm{~B}$ & 30 \\
\hline \multicolumn{2}{|l|}{ T-stage (n) } \\
\hline T0 & 2 \\
\hline $\mathrm{T} 1$ & 16 \\
\hline $\mathrm{T} 2$ & 30 \\
\hline T3 & 18 \\
\hline $\mathrm{T} 4$ & 20 \\
\hline \multicolumn{2}{|l|}{$N$-stage (n) } \\
\hline No & 8 \\
\hline N1 & 4 \\
\hline $\mathrm{N} 2$ & 59 \\
\hline N3 & 14 \\
\hline unknown & 1 \\
\hline \multicolumn{2}{|l|}{ Treatment (n) } \\
\hline concurrent RT and $\mathrm{CHT}$ & 37 \\
\hline sequential RT en $\mathrm{CHT}$ & 42 \\
\hline RT alone & 7 \\
\hline
\end{tabular}

\section{Results}

\section{Patients}

The characteristics of the 86 patients are presented in Table 1. Median age was 67 years, ranging from 45 to 83 years. Three patients with stage IIB (of whom one was treated for a recurrent disease), 53 with stage IIIA and 30 patients with stage IIIB were included in the study. Seven patients were treated with radiotherapy alone, 42 with sequential chemoradiotherapy, and 37 with concurrent chemoradiotherapy. Three of the 42 patients who received sequential chemotherapy and radiotherapy did not complete the planned three courses of chemotherapy due to malaise, a gastrointestinal bleeding and an exacerbation of pancreatitis. Eighty-one percent of the patients was treated with a radiation prescription dose of $66 \mathrm{~Gy}$, one patient received $67.5 \mathrm{~Gy}$ in 2.25 Gy fractions (stage IIB patient) and 15 received 
less than 66 Gy due to clinical deterioration or the development of metastatic disease during the course of treatment. As a consequence the median irradiated dose was 66 Gy with a range from 32 to 67.5 Gy. Median follow-up for all patients was 12 months (range, 1-35 months), and for patients still alive at study closure date it was 17 months (range, 5-39 months).

\section{Treatment outcome}

The median overall survival among the 70 patients receiving a radiation dose of 66 Gy was 29.7 months (Figure 1). The follow-up of patients treated with radiotherapy alone and concurrent chemoradiotherapy was too short to enable the calculation of the median overall survival time. In patients treated with sequential chemotherapy and radiotherapy the median overall survival was 29.7 months. Irrespective of the treatment modality, this resulted in an overall survival rate of $71 \%( \pm 11 \%$; $95 \% \mathrm{CI})$ after one year and $56 \%( \pm 14 \%)$ after two years for patients receiving $66 \mathrm{~Gy}$. In patients treated with radiation only, 1 - and 2-year overall survival rates were $80 \%(55-100 \%)$ and $60 \%$ (18-100\%), respectively. In patients treated by sequential chemotherapy and radiotherapy 1 - and 2-year overall survival rates were $66 \%$ $( \pm 17 \%)$ and $55 \%( \pm 20 \%)$, and in patients treated with concurrent chemoradiotherapy $74 \%( \pm 16 \%)$ and $56 \%$ $( \pm 22 \%)$, respectively. No statistically significant differences in overall survival between the treatment groups were observed.

The median metastasis-free survival of patients receiving a radiation dose of 66 Gy was not reached in any of the treatment schedules, and after 1 and 2 years, the metastasis-free survival rates were both $73 \%$ $( \pm 13 \%)$ (Figure 2$)$. Among patients receiving a radiation dose of 66 Gy without additional chemotherapy, the 1- and 2-year metastasis-free survival rates were both 75\% (33-100\%). Among patients treated with sequential chemotherapy and 66 Gy of radiotherapy, the rates were $73 \%( \pm 16 \%)$ and $66 \%( \pm 20 \%)$ at 1 and 2 years, respectively. In patients concurrently treated with chemoradiotherapy, the metastasis-free survival was $73 \%( \pm 16 \%)$ at both time-points. No statistically significant difference between the treatment groups was observed. Most commonly, distant metastases occurred simultaneously at multiple sites (5 patients) or separately in bone ( 8 patients), brain ( 5 patients) or liver (3 patients).

\section{Acute pulmonary and esophageal toxicity}

Table 2 summarizes the acute treatment-related pulmonary and esophageal toxicity of the patients. Of all patients, $13(15 \%)$ experienced no acute pulmonary toxicity, $51(60 \%)$ mild dry cough or dyspnea on exertion, and 20 (23\%) grade 2 symptoms. Pulmonary toxicity did not statistically differ between treatment schedules. No acute esophageal toxicity was observed in 12 patients (13\%), slight symptoms requiring no or non-narcotic analgesics in $43(50 \%)$ and esophageal toxicity requiring narcotic analgesics and adapted diet in 30 patients (35\%). Thereby, esophageal toxicity differed statistically significant between patients undergoing sequential or concurrent chemoradiotherapy, unfavorable for the latter $(p=0.013)$. Neither grade 3 nor grade 4 pulmonary or esophageal toxicity was observed and no patient died of treatment-related causes.

\section{Discussion}

The number of clinical studies evaluating treatment outcome on the use of IMRT for locally advanced NSCLC is

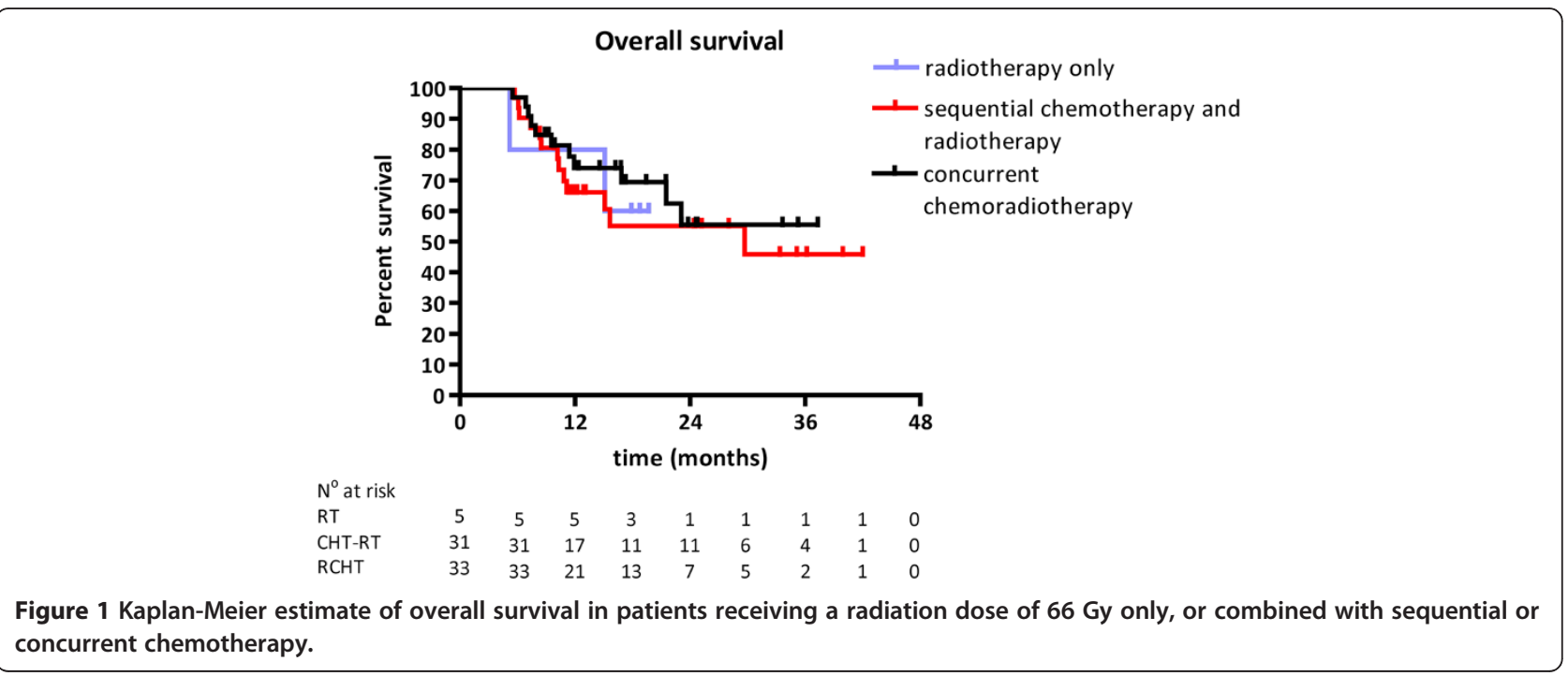




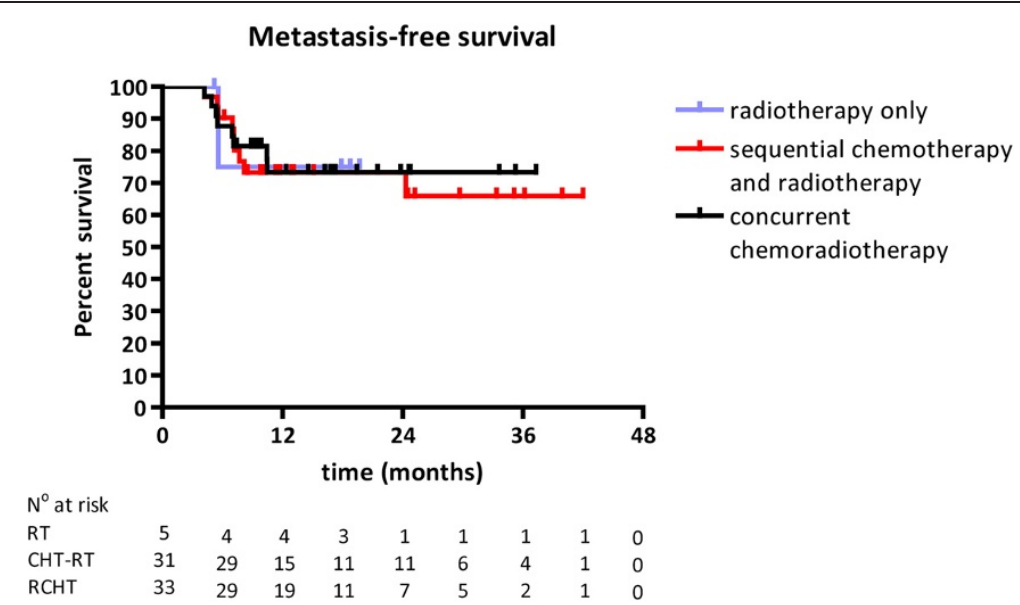

Figure 2 Kaplan-Meier estimate of metastasis-free survival in patients receiving a radiation dose of 66 Gy only, or combined with sequential or concurrent chemotherapy.

limited. The results reported in our study encourage the use of IMRT in patients with irresectable NSCLC. We found among all patients receiving 66 Gy 1- and 2-year overall survival rates of $71 \%$ and $56 \%$, respectively, and a median overall survival of 29.7 months.

Several studies have addressed treatment outcome using 3D-CRT or IMRT for advanced stage NSCLC patients. Nakayama et al. compared the clinical results of high dose 3D-CRT (66 to 84 Gy) with those of conventional two-dimensional radiotherapy (56 to $66 \mathrm{~Gy}$ ) for patients with Stage III NSCLC [13]. The overall survival rates at 3 years were $9.1 \%$ (95\% CI, $0.7-18.9 \%)$ in the conventional group and $31.0 \%$ (95\% CI, 18.943.1\%) in the high-dose group. Wang et al. retrospectively evaluated the outcome of 237 stage III NSCLC patients treated with radiotherapy alone, sequential chemoradiotherapy or concurrent chemoradiotherapy using 3D-CRT [9]. The median overall survival of the entire cohort was 12.6 months, and 2- and 5-year overall survival rates were $22.4 \%$ and $10.0 \%$, respectively. Recently, the Memorial Sloan-Kettering Cancer Center

Table 2 Frequency (and \% of patients in the respective treatment group) of acute pulmonary and esophageal toxicity in patients according to treatment

\begin{tabular}{lcrrccc}
\hline & \multicolumn{3}{c}{ Pulmonary toxicity } & \multicolumn{3}{c}{ Esophageal toxicity } \\
\hline Treatment & Grade 0 & Grade 1 & Grade 2 & Grade 0 & Grade 1 & Grade 2 \\
RT $^{\text {\$ }}$ & $0(0)$ & $4(57)$ & $3(43)$ & $2(29)$ & $3(43)$ & $2(29)$ \\
CHT-RT $^{\#}$ & $4(10)$ & $26(62)$ & $10(24)$ & $8(19)$ & $24(57)$ & $9(21)$ \\
RCHT & $9(24)$ & $21(57)$ & $7(19)$ & $2(5)$ & $16(43)^{*}$ & $19(51)^{*}$ \\
\hline
\end{tabular}

${ }^{\$} \mathrm{RT}=$ radiotherapy alone; ${ }^{*} \mathrm{CHT}-\mathrm{RT}=$ sequential chemotherapy and radiotherapy; ${ }^{\text {RCHT }}=$ concurrent chemoradiotherapy. ${ }^{*} p=0.013$; chi-square test of sequential versus concurrent chemoradiotherapy. For the sequential chemotherapy and radiotherapy group, numbers on acute pulmonary and esophageal toxicity are missing for 2 patients and 1 patient, respectively. retrospectively reviewed treatment outcome of 55 stage I-IIIB inoperable NSCLC patients with large tumor volumes (GTV $\geq 100 \mathrm{cc}$ ) treated with IMRT [23]. For patients with stage III disease, 2-year local control and overall survival rates were both $58 \%$, respectively, with a median survival time of 25 months. Liao et al. reviewed the records of 91 patients who received treatment with concurrent chemoradiotherapy using 4DCT/IMRT and compared outcome with patients treated with CT/3D-CRT [17]. The hazard ratio for 4DCT/IMRT was 0.64 (95\% CI $0.41-0.98)$ and statistically significant $(p=0.039)$ for the overall survival. Based on these reports on 3D-CRT and IMRT $[8,9,13,19]$, and our observations, we consider IMRT as an effective treatment option for patients with locally advanced NSCLC.

Besides favorable outcome data, no severe treatmentrelated acute pulmonary or esophageal toxicity was observed. In line with previous reports, however, acute esophageal toxicity was enhanced in concurrent schedules compared to sequential chemoradiotherapy $[5,6]$. Sura et al. scored acute toxicity on the RTOG scale and reported six patients (11\%) to experience grade 3 acute pulmonary toxicity and two (4\%) to experience grade 3 acute esophagitis, with no grade $\geq 4$ acute toxicity [23]. Using the CTCAE version 3.0 scoring criteria [24], Yom et al. reported an incidence of grade $\geq 3$ treatment-related pneumonitis in the IMRT group of $8 \%(95 \% \mathrm{CI}, 4 \%-19 \%)$ at 6 and 12 months [16].

Differences in treatment outcome and toxicity may be attributable to different GTV volumes, delivered treatment schedules and radiation dose, tumor stage and the number of patients included in the study. In our study, the patient's performance status was not explicitly taken into account. Nevertheless, the treatment choice is dependent on the performance score and only patients in good general condition, i.e., Karnofsky index 
$\geq 70 \%$, were considered candidates for concurrent chemoradiotherapy.

There are some concerns with respect to the use of IMRT in daily practice. One such concern is the effect of respiratory motion on the accuracy of IMRT delivery [25]. However, several studies have shown that dose variation, introduced by organ motion, almost completely disappears when delivering fractionated radiotherapy [26-28]. Furthermore, in our institute a slow$\mathrm{CT}$ scan is routinely performed for treatment planning purposes incorporating all tumor motion into the definition of the GTV. By doing so, the respiratory motion has largely the same effect on IMRT dose distributions as on conformal radiotherapy techniques. Another concern of IMRT is low-dose radiation exposure of larger volumes of unaffected lung tissue. In the era of 3DCRT, the mean lung dose (MLD; [29]) and the volume of unaffected lung tissue receiving a dose of at least 20 Gy (V20) were most often dose-limiting. By applying highly-conformal techniques such as IMRT, however, the MLD alone is more often dose limiting than V20. The reason for this is that by increasing the number of beams, i.e., adding beams from various angles, a larger unaffected lung volume is exposed to a low dose of radiation (below 20 Gy, i.e., V20 decreases). Furthermore, with conformal radiotherapy the PTV is always covered by all beams at all moments while an intrinsic feature of IMRT is that with IMRT, the entire PTV is not always covered by the beam in all its segments. This allows giving a higher dose to the PTV while V20 is unaffected, but with a higher MLD. That is explained by a somewhat higher total dose to the body as a result of increased monitor units delivered by more radiation beams [30,31]. As a consequence more radiationinduced cancers might be expected in long-term survivors [31,32].

Despite these concerns, IMRT outcome results are very promising and the toxicity rates acceptable, which supports the consideration of IMRT as an effective and useful radiotherapy technique for the treatment of locally advanced NSCLC.

Notwithstanding the encouraging results of IMRT already reported, more research is needed to further improve outcome for locally advanced NSCLC. To improve local control and outcome with modern radiotherapy techniques in stage III NSCLC patients, a modeling study, investigating the therapeutic gain of individualized dose prescription with dose escalation for various hypofractionation schemes, has recently been conducted at our institution [33]. The encouraging findings have resulted in a clinical phase II trial in which stage III NSCLC patients eligible for (concurrent chemo)radiotherapy are treated with individualized escalated dose.

\section{Conclusions}

This retrospective cohort study in 86 patients with locally advanced irresectable non-small cell lung cancer shows that IMRT is an effective technique with acceptable acute toxicity, also when (sequentially or concomitantly) combined with chemotherapy.

\section{Competing interests}

The authors declare to have no conflicts of interest.

\section{Authors' contributions}

SLAG data collection, analysis, preparation of manuscript. EGCT data collection, analysis, preparation of manuscript. OCJS preparation of manuscript. LFdeG-O preparation of manuscript. AT preparation of manuscript. PNS analysis, preparation of manuscript. JB analysis, preparation of manuscript. All authors read and approved the final manuscript.

\section{Author details}

${ }^{1}$ Department of Radiation Oncology, Radboud University Nijmegen Medical Centre, PO Box 9101, Nijmegen 6500 HB, The Netherlands. 'Department of Pulmonary Diseases, Radboud University Nijmegen Medical Centre, PO Box 9101, Nijmegen 6500 HB, The Netherlands. ${ }^{3}$ Department of Nuclear Medicine, Radboud University Nijmegen Medical Centre, PO Box 9101, Nijmegen 6500 HB, The Netherlands. ${ }^{4}$ Department of Pulmonary Diseases, Canisius-Wilhelmina Hospital, Nijmegen, The Netherlands.

Received: 24 May 2012 Accepted: 25 August 2012

Published: 7 September 2012

\section{References}

1. Howlader N, Noone AM, Krapcho M, Neyman N, Aminou R, Altekruse SF, Kosary CL, Ruhl J, Tatalovich Z, Cho H, et al: SEER Cancer Statistics Review, 1975-2009 (Vintage 2009 Populations). In Book SEER Cancer Statistics Review, 1975-2009 (Vintage 2009 Populations). City: National Cancer Institute; 2012.

2. Robinson LA, Ruckdeschel JC, Wagner H Jr, Stevens CW: Treatment of nonsmall cell lung cancer-stage IIIA: ACCP evidence-based clinical practice guidelines (2nd edition). Chest 2007, 132:243S-265S.

3. Jett JR, Schild SE, Keith RL, Kesler KA: Treatment of non-small cell lung cancer, stage IIIB: ACCP evidence-based clinical practice guidelines (2nd edition). Chest 2007, 132:266S-276S.

4. Scott WJ, Howington J, Feigenberg S, Movsas B, Pisters K: Treatment of non-small cell lung cancer stage I and stage II: ACCP evidence-based clinical practice guidelines (2nd edition). Chest 2007, 132:234S-242S.

5. Auperin A, Le Pechoux C, Rolland E, Curran WJ, Furuse $K$, Fournel $P$, Belderbos J, Clamon G, Ulutin HC, Paulus R, et al: Meta-analysis of concomitant versus sequential radiochemotherapy in locally advanced non-small-cell lung cancer. J Clin Oncol 2010, 28:2181-2190.

6. De Ruysscher D, Botterweck A, Dirx M, Pijls-Johannesma M, Wanders R, Hochstenbag M, Dingemans AM, Bootsma G, Geraedts W, Simons J, et al: Eligibility for concurrent chemotherapy and radiotherapy of locally advanced lung cancer patients: a prospective, population-based study. Ann Oncol 2009, 20:98-102.

7. Perez CA, Bauer M, Edelstein S, Gillespie BW, Birch R: Impact of tumor control on survival in carcinoma of the lung treated with irradiation. Int $J$ Radiat Oncol Biol Phys 1986, 12:539-547.

8. Rengan R, Rosenzweig KE, Venkatraman E, Koutcher LA, Fox JL, Nayak R, Amols $\mathrm{H}$, Yorke $\mathrm{E}$, Jackson A, Ling CC, Leibel SA: Improved local control with higher doses of radiation in large-volume stage III non-small-cell lung cancer. Int J Radiat Oncol Biol Phys 2004, 60:741-747.

9. Wang L, Correa CR, Zhao L, Hayman J, Kalemkerian GP, Lyons S, Cease K, Brenner D, Kong FM: The effect of radiation dose and chemotherapy on overall survival in 237 patients with Stage III non-small-cell lung cancer. Int J Radiat Oncol Biol Phys 2009, 73:1383-1390.

10. Belderbos JS, Heemsbergen WD, De Jaeger K, Baas P, Lebesque JV: Final results of a Phase I/II dose escalation trial in non-small-cell lung cancer using three-dimensional conformal radiotherapy. Int J Radiat Oncol Biol Phys 2006, 66:126-134 
11. van Baardwijk A, Wanders S, Boersma L, Borger J, Ollers M, Dingemans AM, Bootsma G, Geraedts W, Pitz C, Lunde R, et al: Mature results of an individualized radiation dose prescription study based on normal tissue constraints in stages I to III non-small-cell lung cancer. J Clin Oncol 2010, 28:1380-1386

12. Kong FM, Hayman JA, Griffith KA, Kalemkerian GP, Arenberg D, Lyons S, Turrisi A, Lichter A, Fraass B, Eisbruch A, et al: Final toxicity results of a radiation-dose escalation study in patients with non-small-cell lung cancer (NSCLC): predictors for radiation pneumonitis and fibrosis. Int $J$ Radiat Oncol Biol Phys 2006, 65:1075-1086.

13. Nakayama H, Satoh H, Kurishima K, Ishikawa H, Tokuuye K: High-dose conformal radiotherapy for patients with stage III non-small-cell lung carcinoma. Int J Radiat Oncol Biol Phys 2010, 78:645-650.

14. Christian JA, Bedford JL, Webb S, Brada M: Comparison of inverse-planned three-dimensional conformal radiotherapy and intensity-modulated radiotherapy for non-small-cell lung cancer. Int J Radiat Oncol Biol Phys 2007, 67:735-741.

15. RTOG Acute Radiation Morbidity Scoring Criteria. http://www.rtog.org/Research Associates/AdverseEventReporting/AcuteRadiationMorbidityScoringCriteria.aspx.

16. Yom SS, Liao Z, Liu HH, Tucker SL, Hu CS, Wei X, Wang X, Wang S, Mohan R, Cox JD, Komaki R: Initial evaluation of treatment-related pneumonitis in advanced-stage non-small-cell lung cancer patients treated with concurrent chemotherapy and intensity-modulated radiotherapy. Int J Radiat Oncol Biol Phys 2007, 68:94-102.

17. Liao ZX, Komaki RR, Thames HD Jr, Liu HH, Tucker SL, Mohan R, Martel MK, Wei X, Yang K, Kim ES, et al: Influence of technologic advances on outcomes in patients with unresectable, locally advanced non-small-cell lung cancer receiving concomitant chemoradiotherapy. Int J Radiat Oncol Biol Phys 2010, 76:775-781.

18. Scrimger RA, Tome WA, Olivera GH, Reckwerdt PJ, Mehta MP, Fowler JF: Reduction in radiation dose to lung and other normal tissues using helical tomotherapy to treat lung cancer, in comparison to conventional field arrangements. Am J Clin Oncol 2003, 26:70-78.

19. Liu HH, Wang X, Dong L, Wu Q, Liao Z, Stevens CW, Guerrero TM, Komaki R, Cox JD, Mohan R: Feasibility of sparing lung and other thoracic structures with intensity-modulated radiotherapy for non-small-cell lung cancer. Int J Radiat Oncol Biol Phys 2004, 58:1268-1279.

20. Prescribing, Recording, and Reporting Photon Beam Therapy (Report 50). In Book Prescribing, Recording, and Reporting Photon Beam Therapy (Report 50). City: International Commission on Radiation Units \& Measurements; 1993.

21. Prescribing, Recording and Reporting Photon Beam Therapy (Report 62); Supplement to ICRU Report 50. In Book Prescribing, Recording and Reporting Photon Beam Therapy (Report 62); Supplement to ICRU Report 50. City: International Commission on Radiation Units and Measurements; 1999.

22. de Boer HC, Heijmen BJ: A protocol for the reduction of systematic patient setup errors with minimal portal imaging workload. Int J Radiat Oncol Biol Phys 2001, 50:1350-1365.

23. Sura S, Gupta V, Yorke E, Jackson A, Amols H, Rosenzweig KE: Intensitymodulated radiation therapy (IMRT) for inoperable non-small cell lung cancer: the Memorial Sloan-Kettering Cancer Center (MSKCC) experience. Radiother Oncol 2008, 87:17-23.

24. Common Terminology Criteria for Adverse Events (CTCAE) version 3.0. http:// ctep.cancer.gov/protocolDevelopment/electronic_applications/ctc.htm ctc_30.

25. Fenwick JD, Nahum AE, Malik ZI, Eswar CV, Hatton MQ, Laurence VM, Lester JF, Landau DB: Escalation and intensification of radiotherapy for stage III non-small cell lung cancer: opportunities for treatment improvement. Clin Oncol (R Coll Radiol) 2009, 21:343-360.

26. Bortfeld T, Jokivarsi K, Goitein M, Kung J, Jiang SB: Effects of intra-fraction motion on IMRT dose delivery: statistical analysis and simulation. Phys Med Biol 2002, 47:2203-2220.

27. Duan J, Shen S, Fiveash JB, Popple RA, Brezovich IA: Dosimetric and radiobiological impact of dose fractionation on respiratory motion induced IMRT delivery errors: a volumetric dose measurement study. Med Phys 2006, 33:1380-1387.

28. Jiang SB, Pope C, Al Jarrah KM, Kung JH, Bortfeld T, Chen GT: An experimental investigation on intra-fractional organ motion effects in lung IMRT treatments. Phys Med Biol 2003, 48:1773-1784.

29. Kwa SL, Lebesque JV, Theuws JC, Marks LB, Munley MT, Bentel G, Oetzel D, Spahn U, Graham MV, Drzymala RE, et al: Radiation pneumonitis as a function of mean lung dose: an analysis of pooled data of 540 patients. Int J Radiat Oncol Biol Phys 1998, 42:1-9.

30. Intensity-modulated radiotherapy: current status and issues of interest. Int J Radiat Oncol Biol Phys 2001, 51:880-914.

31. Hall EJ: Intensity-modulated radiation therapy, protons, and the risk of second cancers. Int J Radiat Oncol Biol Phys 2006, 65:1-7.

32. Brenner DJ, Doll R, Goodhead DT, Hall EJ, Land CE, Little JB, Lubin JH, Preston DL, Preston RJ, Puskin JS, et al: Cancer risks attributable to low doses of ionizing radiation: assessing what we really know. Proc Natl Acad Sci USA 2003, 100:13761-13766.

33. Hoffmann AL, Troost EG, Huizenga H, Kaanders JH, Bussink J: Individualized Dose Prescription for Hypofractionation in Advanced Non-Small-Cell Lung Cancer Radiotherapy: an in silico Trial. Int J Radiat Oncol Biol Phys 2012, 83:1596-1602.

\section{doi:10.1186/1748-717X-7-150}

Cite this article as: Govaert et al:: Treatment outcome and toxicity of intensity-modulated (chemo) radiotherapy in stage III non-small cell lung cancer patients. Radiation Oncology 2012 7:150.

\section{Submit your next manuscript to BioMed Central and take full advantage of:}

- Convenient online submission

- Thorough peer review

- No space constraints or color figure charges

- Immediate publication on acceptance

- Inclusion in PubMed, CAS, Scopus and Google Scholar

- Research which is freely available for redistribution

Submit your manuscript at www.biomedcentral.com/submit
C) Biomed Central 